\title{
Brassinosteroid-mediated regulation of agronomic traits in rice
}

\author{
Cui Zhang $\cdot$ Ming-yi Bai $\cdot$ Kang Chong
}

Received: 22 January 2014/Accepted: 29 January 2014/Published online: 26 March 2014

(c) The Author(s) 2014. This article is published with open access at Springerlink.com

\begin{abstract}
Key message Brassinosteroids have important roles in plant development. This review focuses on the agronomic traits regulated by brassinosteroids in rice.

Abstract Brassinosteroids (BRs) are a group of steroid phytohormones with wide-ranging biological activity. Genetic, genomic and proteomic studies have greatly advanced our understanding of BR signaling in Arabidopsis and revealed a connected signal transduction pathway from the cell surface receptor kinase BRASSINOSTEROID-INSENSITIVE1 (BRI1) and BRI1-ASSOCIATED RECEPTOR KINASE 1 (BAK1) to the BRASSINAZOLE-RESISTANT1 (BZR1) family of transcription factors and their targets mediating physiological functions. However, compared with the dicot model plant Arabidopsis, much less is known about BR signaling in rice, which is a monocot. In this review, we provide an update on the progress made by BR studies in rice and discuss how BR regulates various important agronomic traits to determine rice grain yield. Specifically, we discuss the function of novel components including LEAF AND
\end{abstract}

Communicated by N. Stewart.

\section{Zhang}

Institute of Genetics and Development Biology, Chinese

Academy of Sciences, Beijing 100101, China

\section{Bai}

The Key Laboratory of Plant Cell Engineering and Germplasm Innovation, Ministry of Education, School of Life Sciences,

Shandong University, Jinan 250100, China

\section{K. Chong ( $\square)$}

Institute of Botany, Chinese Academy of Sciences,

Beijing 100093, China

e-mail: chongk@ibcas.ac.cn
TILLER ANGLE INCREASED CONTROLLER (LIC), DWARF and LOW-TILLERING (DLT), DWARF1 (D1) and TAIHU DWARF1 (TUD1) in rice BR signaling, and provide a rice BR-signaling pathway model that involves a BRI1-dependent pathway as well as a G-protein $\alpha$ subunitmediated signaling pathway. The recent significant advances in our understanding of BR-mediated molecular mechanisms underlying agronomic traits will be of great help for rice molecular breeding.

Keywords Brassinosteroids - Signaling - Homeostasis · Rice agronomic traits · Grain yield
Abbreviations
BR Brassinosteroid
GA Gibberellic acid
ABA Abscisic acid

\section{Introduction}

Rice (Oryza sativa L.) is one of the most important food crops and feeds more than half of the world population. Increasing crop yield is a major challenge for modern agriculture. Rice plant architecture is crucial for grain yield and is determined by plant height, leaf angle, tiller number, and panicle morphology. Phytohormones such as brassinosteroids (BRs) play important roles in development of plant architecture, and rice BR-related mutants such as $d 61$, $d 2$, BR-deficient dwarf 1 (brdl), and dlt show dwarfism and erect leaves (Yamamuro et al. 2000; Hong et al. 2005; Tong et al. 2009). This suggests that manipulation of BR biosynthesis or signaling to modify rice architecture could be a feasible approach for improving rice yield. 
Brassinosteroids are a class of plant-specific steroidal hormones that are structurally related to animal and insect steroids. Brassinolide (BL), the most biologically active and the naturally occurring form of the BRs was first isolated and purified from Brassica napus pollen in Grove et al. (1979). Since then, more than $50 \mathrm{BL}$ analog have been identified (Fujioka and Sakurai 1997). BRs have been shown to regulate various biological processes in plants including seed germination, stomata formation, vascular differentiation, plant architecture, flowering, male fertility and senescence in Arabidopsis (Clouse and Sasse 1998). Exogenously applied bioactive BRs increase the resistance of plants to a variety of stresses, including both biotic and abiotic stresses (Li 2010). BRs have widely been used since the 1980s to increase yield in crops and vegetables. In rice, BRs affect many agricultural traits that influence grain yield, including plant height, leaf angle, grain size, and tiller number (Ikekawa and Zhao 1991; Khripach et al. 2000).

Extensive genetic, genomic and proteomic studies have identified all major BR-signaling components in Arabidopsis and elucidated the cross talk of BR with other hormonal and environmental signals. Numerous reviews have described current knowledge about the molecular structure of the BR-signaling network (Clouse 2011; Tong and Chu 2012; Vriet et al. 2013; Wang et al. 2012). Compared with the tremendous progress of BR-signaling studies in Arabidopsis, much less is known in the monocot model plant rice (Hao et al. 2013). Recently, several important BR-signaling components have been identified in rice, and functional studies of these genes provide promising tools for molecular breeding with modification of the BR-signaling network. In this review, we will briefly introduce BR biosynthesis and signaling in Arabidopsis and then focus on BR functional studies in rice.

\section{BR signaling in Arabidopsis}

The signal transduction pathway for BRs from perception to downstream regulation has been extensively studied (Wang et al. 2012). In the absence of BRs, BRI1 KINASE INHIBITOR 1 (BKI1) prevents the heterodimerization of BRI1 with BRI1-ASSOCIATED RECEPTOR KINASE 1 (BAK1) to inactivate BRI1 (Fig. 1) (Jaillais et al. 2011; Wang and Chory 2006). In the presence of BRs, BRs directly interact with the LRR domains of BRI1 and SOMATIC EMBRYO-GENESIS RECEPTOR KINASE (SERK) to form a BRI1-BR-SERK complex, and induce BRI1 and SERK transphosphorylation of each other to activate the BRI1 signaling pathway (Hothorn et al. 2011; Kinoshita et al. 2005; Li and Chory 1997; Li et al. 2002; Nam and Li 2002; Santiago et al. 2013; She et al. 2011; Wang et al. 2008a, b). Activated BRI1 phosphorylates
BKI1 on Tyr211, leading to the disassociation of BKI1 from the plasma membrane. Phosphorylated BKI1 interacts with 14-3-3 proteins and releases its inhibition of BZR1 and BZR2 (also named BES1 for BRI1-EMS-SUPPRESSOR 1) (Wang et al. 2011). Activated BRI1 phosphorylates BR-SIGNALING KINASEs (BSKs) and CONSTITUTIVE DIFFERENTIAL GROWTH 1 (CDG1), which subsequently activate the BRI1-SUPPRESSOR 1 (BSU1) phosphatase (Kim et al. 2009, 2011; Mora-Garcia et al. 2004; Tang et al. 2008). BSU1 inactivates BRASSINOSTEROID-INSENSITIVE 2 (BIN2) through dephosphorylation, thus relieving BIN2's suppression of BZR1 and BZR2/ BES1 (He et al. 2002; Li and Nam 2002; Wang et al. 2002; Yin et al. 2002). Upon BR-induced inactivation of BIN2, BZR1 and BES1 are rapidly dephosphorylated by PHOSPHATASE 2A (PP2A) (Tang et al. 2011). Dephosphorylated BZR1 and BES1 dissociate from 14-3-3 proteins and accumulate in the nucleus to regulate the expression of more than one thousand downstream genes (He et al. 2005; Sun et al. 2010; Yin et al. 2005). Yeast two-hybrid and pull-down assays demonstrated that BZR1 interacts with a cyclophilin, CYP20-2, which alters the conformation and enhances phosphorylation of BZR1 (Zhang et al. 2013). BZR1 and BES1 can both regulate BR-related genes directly or through interaction with other transcription factors, such as BES1-INTERACTING Myc-LIKE1 (BIM1) and INTERACT-WITH-SPT6 (IWS) (Li et al. 2010; Yin et al. 2005). Recent studies have revealed that BR-induced SUPPRESSOR of BRI1 (SBI1) methylates PP2A, and activated PP2A dephosphorylates BRI1 to attenuate BR signaling (Fig. 1) (Di Rubbo et al. 2011; Wu et al. 2011).

Although the framework of the BR-signaling network has been established and genome-wide analysis has provided a global view of $\mathrm{BR}$ function, most of the $\mathrm{BR}$ response targets and their links with other hormones and environmental signals still remain to be characterized (Hao et al. 2013). In Arabidopsis, the BR-signaling pathway interacts with signaling of other hormones such as GAs (Bai et al. 2012), ABAs (Zhang et al. 2009b; Zhang et al. 2011), and Strigolectone (Wang et al. 2013) to regulate plant growth and development as well as responses to stress (Table 1).

\section{BR signaling in rice}

Whereas BR biosynthesis and signaling are well understood in Arabidopsis, in rice a few components have been characterized either by forward or reverse genetics (Fig. 1). For some BR components such as OsBRI1, OsBAK1, OsGSK1 and OsBZR1, rice orthologs of the known Arabidopsis genes have been found, and play conserved functions in the two species. However, orthologous 


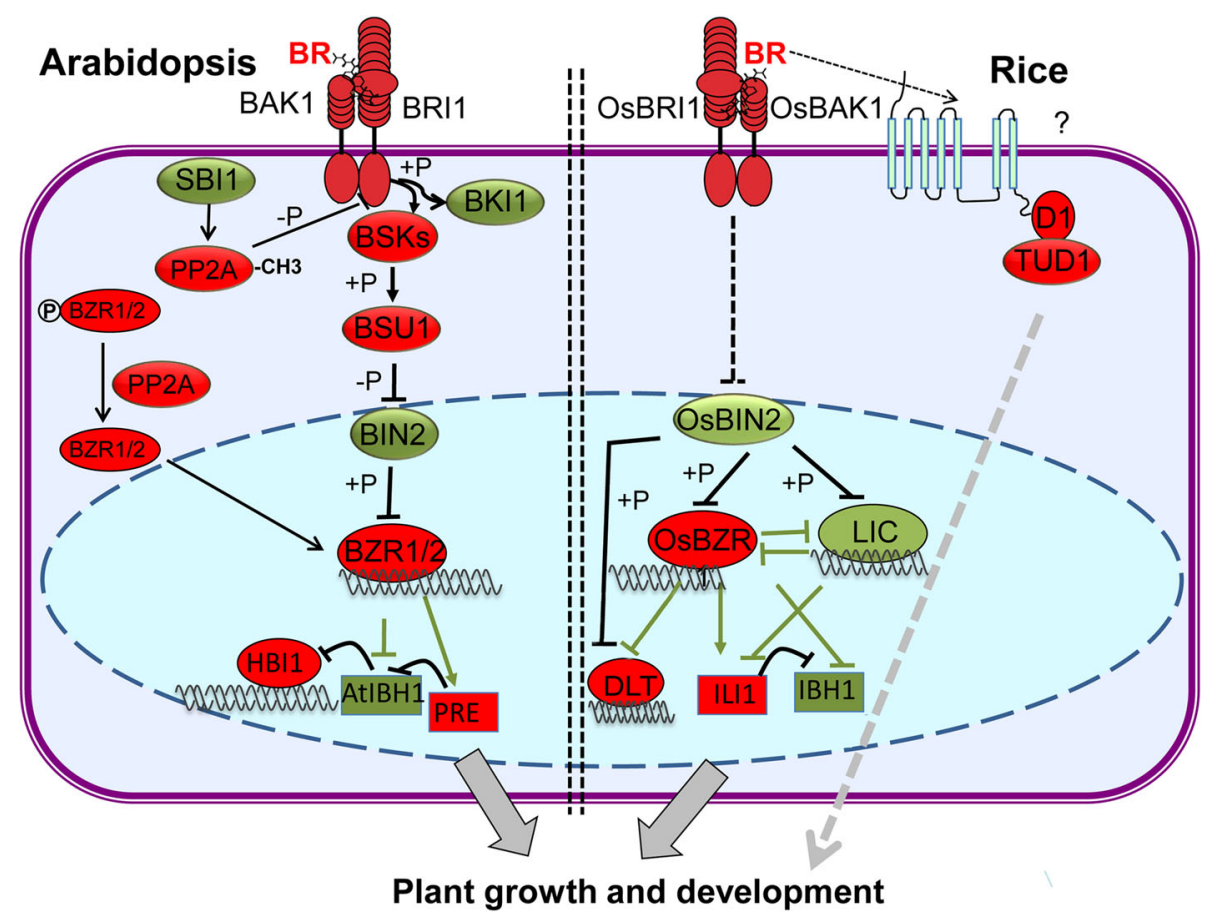

Fig. 1 BR-signaling pathways in rice and Arabidopsis. The left panel shows the BR signal transduction pathway in Arabidopsis. BR directly interacts with BRI1 and BAK1 to form the BRI1-BR-BAK1 complex. Sequential transphosphorylation between BRI1 and BAK1 activates BRI1, which then phosphorylates BSKs/CDG1. The active BSKs/CDG1 phosphorylates BSU1, which dephosphorylates and inactivates BIN2. BZR1 and BES1/BZR2 are dephosphorylated by PP2A and move into the nucleus to induce expression of $P R E 1$, but repress $I B H 1$ expression. PRE1, IBH1 and HBI1 form an antagonistic cascade to regulate plant growth. SBI1 (SUPPRESSOR OF BRI1) is involved in the deactivation of BRI1 through methylation of PP2A.

components of Arabidopsis BR signaling such as PP2A, BSKs and BSU1 have not been identified in rice up to now. Other components including OsLIC, OsDLT and OsTUD1 have been identified in rice but have no orthologs in Arabidopsis, indicating that there are some BR functions specific to rice.

The first identified rice BR-insensitive mutant, $d 61$, was defective in an orthologous gene of BRI1. Loss-of-function mutants of OsBRI1, $d 61-1$ and $d 61-2$ show BR insensitivity, erect leaves, dwarf culms, abnormal skotomorphogenesis, and disorganized microtubule arrangement in cells from the non-elongated internodes, suggesting BRs play an important role in rice development ( $\mathrm{Li}$ et al. 2009; Nakamura et al. 2006; Wang et al. 2007; Yamamuro et al. 2000).

The rice genome contains four genes homologous to $B A K 1$, among which $O s B A K 1$ is the closest relative of $B A K 1$. OsBAK1 can directly interact with OsBRI1, and overexpression of $O s B A K 1$ in transgenic plants causes BR hypersensitivity and partly suppresses both Arabidopsis bril-5 and rice $d 61-1$ mutant phenotypes, suggesting that
The right panel shows the BR-signaling pathway in rice. BR binding to OsBRI1 promotes association with OsBAK1, and inactivates OsBIN2 via an unknown mechanism. OsBIN2 phosphorylates OsBZR1, LIC and DLT, and inhibits their activity. OsBZR1 induces the expression of $I L I I$, but represses the expression of $I B H 1, L I C$ and $D L T$; whereas LIC represses the expression of OsBZR1. The heterotrimeric G-protein $\alpha$ subunit known as D1/RGA1 in rice is involved in another BR-signaling pathway in which D1/RGA1 and TUD1 act together to mediate BR signaling. Red indicates the components play positive roles in BR signaling, whereas green denotes the components that play negative roles

BAK1 has conserved functions in rice and Arabidopsis (Wang et al. 2007; Li et al. 2009).

OsGSK1 is a BIN2 homolog and is involved in BR signaling and stress responses (Koh et al. 2007). Overexpression of OsGSK1 in Arabidopsis leads to plant dwarfism, similar to the phenotype of the gain-of-function mutant bin2-1. The T-DNA knockout mutant of OsGSK1 shows greater tolerance of cold, heat, salt and drought stresses, indicating that OsGSK1 has important functions in stress responses.

OsBZR1 is the closest ortholog of BZR1 and BES1, and functions as a positive regulator of BR signaling. Suppression of $O s B Z R 1$ by RNAi leads to erect leaves, semidwarfism and BR-insensitive phenotypes. Similarly to in Arabidopsis, 14-3-3 proteins bind phosphorylated OsBZR1 to retain OsBZR1 in the cytoplasm (Bai et al. 2007). BZR1 and BES1 directly regulate more than one thousand genes to control multiple biological processes (Sun et al. 2010; $\mathrm{Yu}$ et al. 2011). This highlights the need for genome-wide analysis of OsBZR1-regulated genes to elucidate how BR 
Table 1 The full names of the genes that appear in this review

\begin{tabular}{ll}
\hline Abbreviation & Full name \\
\hline BRI1 & BRASSINOSTEROID-INSENSITIVE1 \\
SERK & SOMATIC EMBRYO-GENESIS RECEPTOR \\
& KINASE \\
BAK1 & BRI1-ASSOCIATED RECEPTOR KINASE 1 \\
BKI1 & BRI1 KINASE INHIBITOR 1 \\
BSK & BR-SIGNALING KINASE \\
CDG1 & CONSTITUTIVE DIFFERENTIAL GROWTH 1 \\
BSU1 & BRI1-SUPPRESSOR 1 \\
BIN2 & BRASSINOSTEROID-INSENSITIVE 2 \\
BZR1 & BRASSINAZOLE-RESISTANT1 \\
BES1 & BRI1-EMS-SUPPRESSOR 1 \\
PP2A & PHOSPHATASE 2A \\
SBI1 & SUPPRESSOR of BRI1 \\
IWS1 & INTERACT-WITH-SPT6 \\
BIM1 & BES1-INTERACTING Myc-LIKE1 \\
LIC & TILLER ANGLE INCREASED CONTROLLER \\
DLT & DWARF and LOW-TILLERING \\
TUD1 & TAIHU DWARF1 \\
ILI1 & Increase Leaf Inclination 1 \\
IBH1 & ILI1 Binding bHLH 1 \\
PRE1 & Paclobutrazol-resistant 1 \\
HBI1 & Homolog of BEE2 Interacting with IBH1 \\
D1 & DWARF1 \\
D2 & DWARF2 \\
D11 & DWARF11 \\
BRD1 & BR-deficient dwarf 1 \\
BRD2 & BR-deficient dwarf 2 \\
DWF1 & DWARF1 \\
DWF4 & DWARF4 \\
CPD & Constitutive Photomorphogenesis and Dwarf \\
DET2 & De-Etiolated-2 \\
ROT3 & CYP90C1 \\
\hline &
\end{tabular}

could act through OsBZR1 to regulate yield-determining traits.

OsILI1 and OsIBH1 interact with each other to regulate rice leaf angle antagonistically. OsBZR1 directly binds to the promoter of these two genes to induce OsILII, but represses OsIBHI expression (Zhang et al. 2009a, b). AtPREI and AtIBHI were identified through searching for orthologous genes of OSILII and OSIBHI, respectively, in Arabidopsis. Analogously to their orthologs in rice, AtPRE1 binds and inhibits AtIBH1 activity to regulate cell elongation. ILI1/PRE1 and IBH1 belong to the helix-loophelix (HLH) family, members of which lack the basic domain required for DNA binding but dimerize with DNAbinding basic HLH (bHLH) transcription factors. Homolog of BEE2 Interacting with IBH1 (HBI1) is a positive regulator of cell elongation downstream of the BR, GA, light and temperature signaling pathways. HBI1 binds to DNA containing G-box element, and IBH1 binding inhibits HBI1 DNA-binding activity, whereas PRE1 interacts with IBH1 to prevent its inhibition of HBI1 (Bai et al. 2012). The conserved function of ILI1/PRE1 and IBH1 in rice and Arabidopsis suggests that it could be fruitful to test whether the rice ortholog of HBI1 is involved in the BR-signaling pathway to control leaf bending.

OsLIC, encoding a novel CCCH-type zinc finger protein, was identified on the basis of its predominant expression in the stem node. Antisense-mediated suppression of $O S L I C$ leads to large leaf and tillering angles, semidwarfism, and decreased numbers of seeds in each panicle, whereas a gain-of-function mutant of OsLIC displays erect leaves and reduced BR sensitivity. Like OsBZR1, OsLIC interacts with OsGSK1 and is phosphorylated by OsGSK1 for retention in the cytoplasm. BR treatment inhibits OsGSK1 activity, thereby inducing OsLIC dephosphorylation and transfer of OsLIC to the nucleus. Nuclear-located OsLIC directly binds to the OsBZRI promoter, which contains CTCGC motifs, and represses OSBZRI transcriptional activity. OsLIC is a direct target of OsBZR1; knockdown of OsBZR1 leads to upregulation of OsLIC. Thus, OsLIC and OsBZR1 represent a pair of antagonistic transcription factors that repress each other during transcription, and their repression strength may depend on the BR level. OsBZRI and OsLIC have different expression patterns: OsBZR1 acts in the presence of low levels of BR to promote signaling, whereas OsLIC is predominantly activated by high levels of BR to brake BR signaling. The dynamics of $B R$ responses in rice development are thus modulated by positive regulator OsBZR1 and negative regulator OsLIC (Fig. 2) (Wang et al. 2008a; Zhang et al. 2012a).

The rice dlt mutant was identified through screening T-DNA insertion dwarf mutants with similar phenotypes to known BR-related mutants. The dlt mutant displays a semidwarf and compact stature, dark-green erect leaves, late flowering, and reduced tillering number (Tong et al. 2009). The dlt mutant is insensitive to BR in lamina joint bending assays, whereas overexpression of OSDLT leads to hypersensitivity to BR. Genetic analysis showed that dlt enhances the dwarf phenotype of the BR-deficient mutant $d 11-2$ and the BR-insensitive mutant $d 61-1$, and overexpression of $O S D L T$ rescues the lamina-inclination phenotype of $d 61-1$ and $O s G S K 2$ antisense lines, suggesting OsDLT acts downstream of OsBRI1 and OsGSK2 to positively regulate BR responses. OsDLT physically interacts with and is phosphorylated by OsGSK2. BR treatment induces OsDLT dephosphorylation through inhibiting OsGSK2 kinase activity. OsDLT expression is negatively regulated by BR and its promoter is bound by OsBZR1 


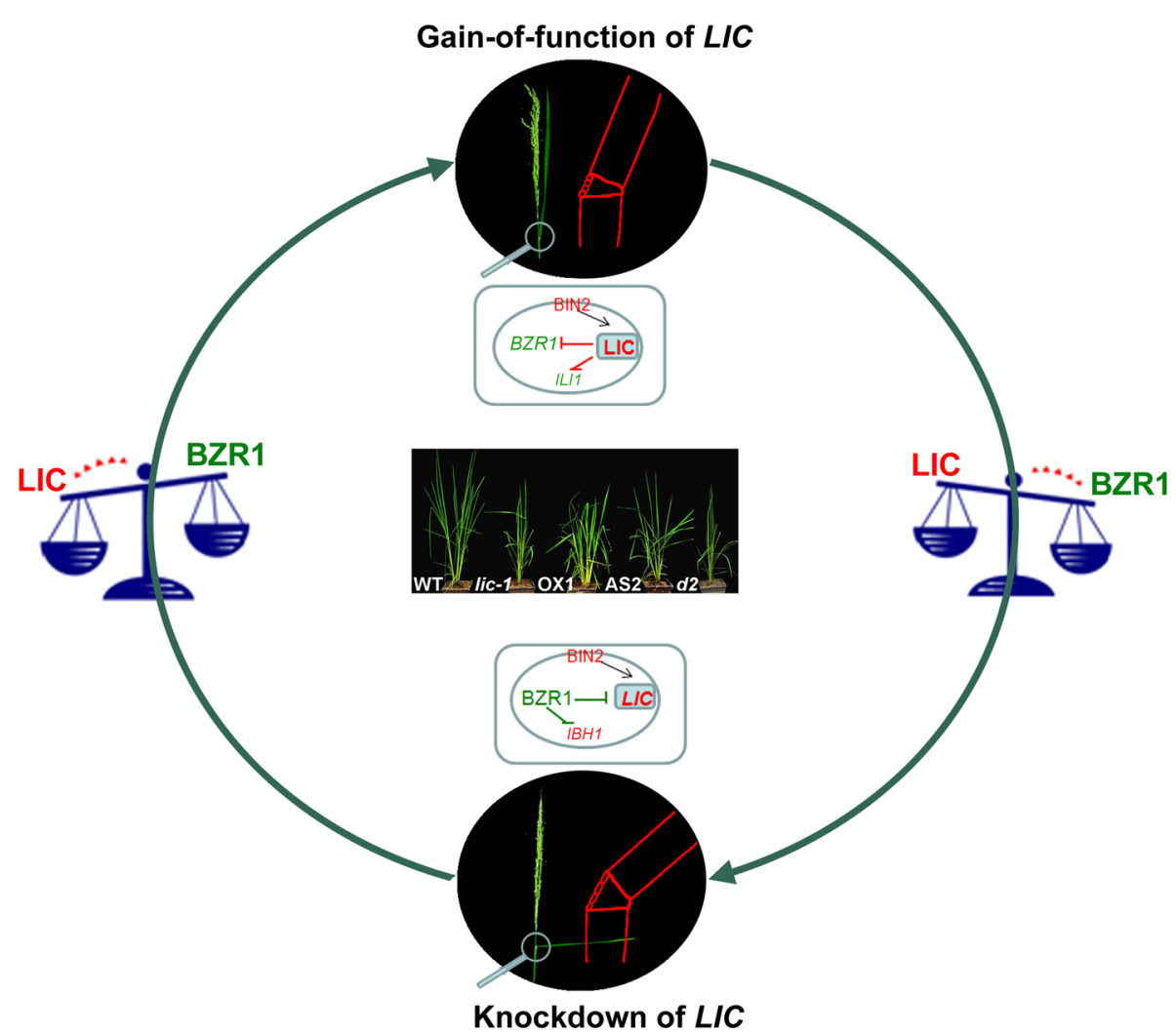

Fig. 2 A diagram of LIC antagonism of BZR1 to balance rice BR signaling. The images in the black circles show the leaf bending of the gain-of function LIC mutant and the antisense line for LIC. The red sketches show the pulvinus (triangle-like, linker between the sheath and leaf) mediating leaf bending. Interior to those images are schematic diagrams of cells, including the nucleus, showing LIC regulation. The $L I C$ overexpression line $1(\mathrm{OX} 1)$ and the gain-offunction mutant (lic-1) display erect leaves similar to the BRbiosynthesis mutant $d 2$; the $L I C$ antisense line 2 (AS2) shows inclined leaves. LIC is a negative regulator of BR signaling while BZR1 is a positive regulator. LIC represses its targets, such as BZRI and ILII, on a transcriptional level and inhibits adaxial cell elongation of the pulvinus in the lic- 1 mutant and the overexpression lines. This causes the plants to show erect leaves. In $L I C$ antisense lines, BZR1 function is dominant. BZR1 represses its targets, such as $L I C$ and $I B H 1$, to promote cell elongation. The plants therefore show increased leaf angle. LIC and BZR1 antagonize each other to balance BR dynamics during development in vitro. Together, these finding suggest that in rice $B R$ signaling, OsDLT and OsBZR1 carry out similar positive functions, while OsLIC plays a negative role. How BR balances the action of these three proteins to regulate rice growth remains unknown (Tong et al. 2009, 2012).

Extensive crosstalk between BRs and GAs in a wide range of biological processes has been reported (De Vleesschauwer et al. 2012). OsGSR1, a member of the GAST family in rice, is induced by GA and suppressed by BRs. OsGSR1 activates BR biosynthesis by directly interacting with DWARF1. Thus, OsGSR1 serves as a point of negative crosstalk between the GA and BR-signaling pathways (Wang et al. 2009). In addition, exogenous BR treatment enhances stability of OsSLR1, a GA signaling repressor in rice (De Vleesschauwer et al. 2012). Expression of OsSLRI increases in response to pathogen infection and BR treatment. However, the crosstalk between BRs and GA is likely complex, as demonstrated by the findings that treatment with BRs down-regulates four DELLA genes in cotton fiber cells (Hu 2011) and that in Arabidopsis, DELLAs directly interact with AtBZR1 and inhibit its DNA binding both in vitro and in vivo (Bai et al. 2012).

G-proteins are involved in an alternative BR-signaling pathway in rice

The $d l$ mutant that was originally identified as being defective in a positive regulator of GA signaling (UeguchiTanaka et al. 2000), has now been shown to have altered BR signaling as well. The $d l$ mutant displays the characteristic BR-related mutant phenotype including shortened second internodes, erect leaves, and constitutive photomorphogenetic growth in the dark. The $d l$ mutant also exhibits decreased sensitivity to BR in many of the aspects examined such as lamina joint bending, coleoptile and second sheath elongation, and root growth inhibition. D1 encodes rice heterotrimeric G-protein $\alpha$ subunit, RGA1, which has been suggested to play important roles in many 
Fig. 3 BR biosynthetic pathway and the enzymes involved in each reaction. Most of the enzymes shown are from Arabidopsis; those in red are the enzymes that have been identified only in rice (Choi et al. 1996; Fujioka et al. 2000; Hong et al. 2003, 2005; Kwon M 2005; Noguchi et al. 2000; Tanabe et al. 2005; Vriet et al. 2013). $C R$ campesterol, $C N$ campestanol, $C T$ cathasterone, $T E$ teasterone, $D T$ dehydroteasterone, $T Y$ typhasterol, $C S$ castasteronel, $B L$ brassinolide

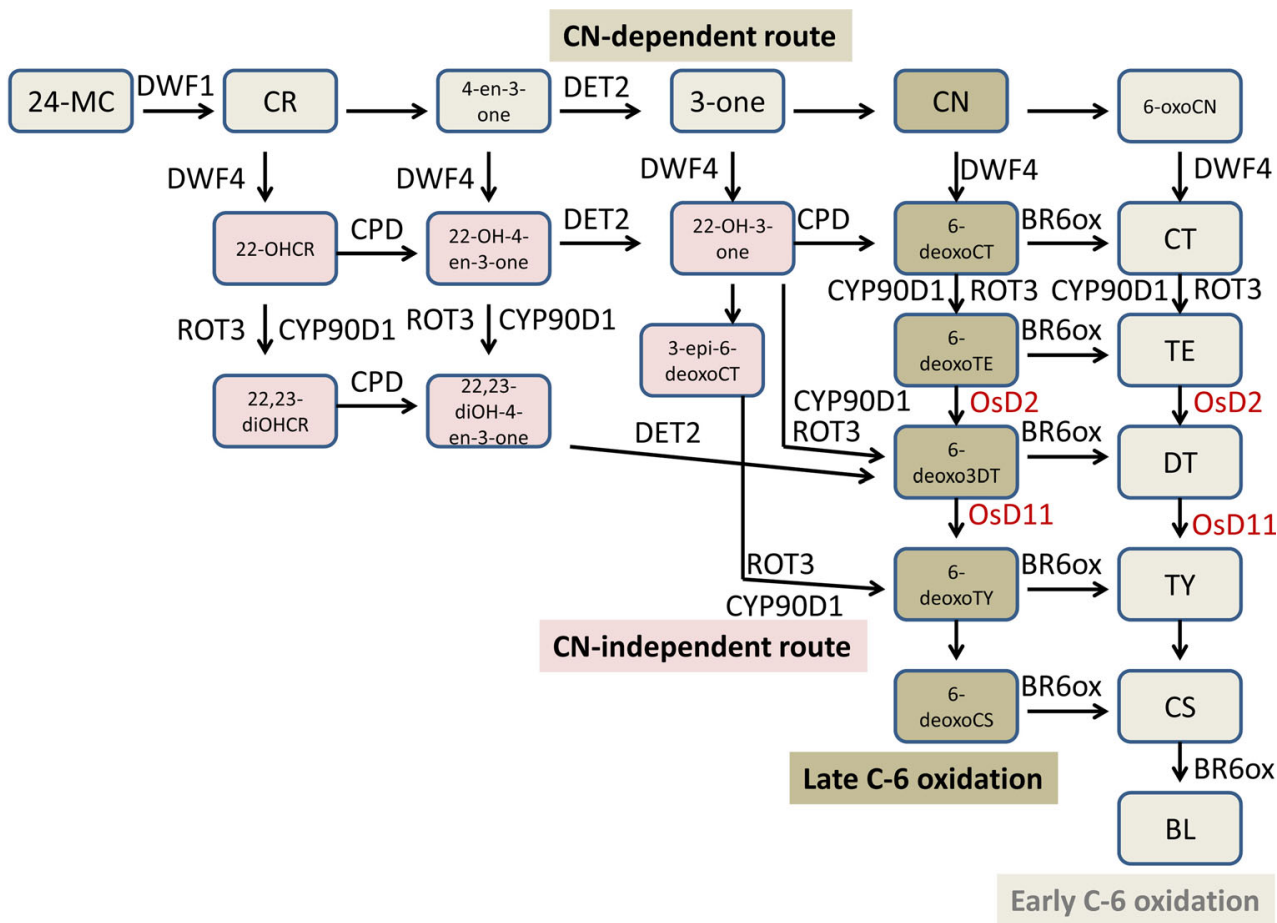

signal transduction processes. BR treatment can repress the expression of BR biosynthetic genes in wild type, and this inhibition is impaired in the OsBRII mutant $d 61$. However, this feedback regulation functions normally in the $d l$ mutant, and the amounts of BR intermediates in the $d l$ mutant are not different with those in WT. Double mutant analysis showed no apparent epistasis between $d 1$ and $d 61$ 7. All of these results suggest that OsD1/RGA1 could be involved in an alternative BR-signaling pathway independent of OsBRI1 (Oki et al. 2009a, b; Wang et al. 2006).

Whether this putative signaling pathway is mediated through another plasma membrane-located BR receptor, such as OsBRL1 or OsBRL3, is still unclear so far. OsBU1 (BR upregulated 1), encoding a HLH protein, is another positive regulator of $\mathrm{BR}$ responses. It is a primary response gene that participates in both the OsBRI1 and OsD1/RGA1 BR-signaling pathways (Oki et al. 2009a, b; Tanaka et al. 2009). Recently, an OsD1/RGA1 genetic interactor, Taihu Dwarf 1 (TUD1), that encodes a functional U-box E3 ubiquitin ligase was reported (Fig. 1). Genetic, phenotypic, and physiological analyses have shown that OsTUD1 is epistatic to $O s D 1 / R G A 1$ and the mutant is less sensitive to BR treatment. OsD1/RGA1 directly interacts with OsTUD1, which demonstrates that OsD1 and OsTUD1 act together to mediate a BR-signaling pathway. This supports the hypothesis that an OsD1/RGA1-mediated BR-signaling pathway acts in rice to influence plant growth and development (Hu et al. 2013). This idea is in agreement with the finding that Arabidopsis heterotrimeric G-protein $\alpha$ subunit (GPA1) is involved in the developmental regulation of BR signaling and biosynthesis (Gao et al. 2008). Although the basic signaling pathway appears to be highly conserved in plants, variation in signaling targets and the specifics in regulation may still underlie the various morphologies found in different species. In rice, there is some evidence for links between BRs and other hormones, such as GAs (Wang et al. 2009). BR-signaling network interactions with other hormone pathways are involved in yield component traits and stress responses (Hao et al. 2013).

BR homeostasis in Arabidopsis and rice

Over the past decades, extensive research has demonstrated the significance of BR homeostasis for normal plant growth. BRs are widely distributed throughout reproductive and vegetative plant tissues and do not travel over long distances in the plant (Symons et al. 2006). Thus, local biosynthesis of BRs is critical for regulation of downstream signaling. To date, almost all of the key enzymes involved in BR biosynthesis have been well characterized in both Arabidopsis and rice (Fig. 3). In Arabidopsis, the BR biosynthesis genes were identified mostly by forward genetics, including DE-ETIOLATED 2 (DET2), CONSTITUTIVE PHOTOMORPHOGENESIS AND DWARF (CPD), DWARF4, CYP724A1, ROT3 (CYP90C1), CYP90D1, BR6OX1 (CYP85A1) and BR6OX2 (CYP85A2) (Ohnishi et al. 2012); (Koka et al. 2000; Sakamoto 2006) (Choe et al. 1998); (Zhang et al. 2012a, b); (Ohnishi et al. 2006); (Bishop et al. 1999; Shimada et al. 2001). Most, if not all, BR biosynthetic enzymes may function as a 
multi-enzyme complex in the ER, enabling the biosynthesis of BL and related BRs by multiple routes (described as a 'metabolic grid' in Fujioka and Yokota 2003).

In rice, several BR biosynthetic enzymes have been identified by mutant screening. OsBRD2, a homolog of Arabidopsis DIMINUTO/DWARF1 (DIM/DWF1) catalyzes the conversion of 24-methylenecholesterol (24-MC) to CR (Hong et al. 2005). OsD2 encodes a P450 (CYP90D2) similar to Arabidopsis CPD and DWF4 (Hong et al. 2003). CYP90D2 and CYP90D3 play redundant roles in multiple $\mathrm{C}-23$ hydroxylation steps in the rice BR biosynthetic pathway (Hong et al. 2003; Sakamoto et al. 2012). OsD11 encodes CYP724B 1 and functions at the C-3 reduction step, catalyzing 6-deoxo 3DT and 3DT to 6-deoxoTY and TY (Tanabe et al. 2005). OsBRD1, a homolog of BR6OX, regulates multiple C-6 oxidation steps (Hong et al. 2002; Mori et al. 2002).

Plants have evolved strategic approaches to regulate BR homeostasis. BRs are transported within the cell from their site of biosynthesis in the ER to the PM (Symons et al. 2008). This transport might involve the formation of BR conjugates with fatty acids or glucose and/or the binding of BRs to transporter proteins (Sasse 2003). Other putative transport mechanisms might involve Sec14 cytosolic factor-mediated vesicle trafficking, and several Sec14 proteins have been identified as BR-regulated proteins in Arabidopsis (Deng et al. 2007), suggesting that there could be regulation of BR homeostasis at the level of transport. BR homeostasis is also regulated via a feedback loop in which the BR biosynthetic genes DWF4, CPD, BR6OXI and ROT3 are down-regulated by the signaling components BZR1 and BES1 in Arabidopsis, and by OsBZR1 and OsDLT in rice (Wang et al. 2002; Yin et al. 2002). Other transcription factors reported to control BR biosynthesis and inactivation include TCP1, CESTA, BRX1, RAVL1 and Pra2 (Choe et al. 2001; Guo et al. 2010; Je et al. 2010; Kang et al. 2001; Mouchel et al. 2006; Poppenberger et al. 2011; Wang et al. 2001). A critical area remaining to be addressed is elucidating the molecular mechanisms that determine the bioactive levels of BRs in response to various developmental and environmental cues.

$\mathrm{BR}$ and rice agronomic traits

\section{Plant height}

The high-yielding semi-dwarf varieties of wheat and rice combined with the application of nitrogen fertilizer contributed to the green revolution, which is a very important trait for high-yield breeding in crops. The reduction in plant height in semi-dwarf varieties led to improved harvest index (grain: straw ratio) and enhanced biomass production (Sakamoto and Matsuoka 2004). The rice stem consists of hollow internodes and jointed nodes, which are usually called culms, and to a large extent the stem contributes to the plant height. Based on the elongation pattern of internodes, rice dwarf mutants were previously categorized into five groups: $\mathrm{dn}, \mathrm{dm}, \mathrm{d} 6, \mathrm{nl}$ and sh (Hong et al. 2004).

BR-deficient and -insensitive mutants display a dwarf phenotype with a specific pattern of internode elongation. Usually, the second internode from the top is shortened completely in plants harboring severe BR mutant alleles and partially in those with mild BR mutant alleles, whereas elongation of the other internodes is affected very little (Yamamuro et al. 2000). This phenotype is known as dmtype dwarfism. OsBRI1 was characterized through the dwarf mutant $d 61$, which has reduced sensitivity to BR. Mutants with a weak allele of $d 61$ fail to elongate the second internode (dm-type mutants) whereas those with the strong allele fail to elongate all internodes except the uppermost one (which is characteristic of d6-type dwarf mutants). OsBRI1 probably regulates internode elongation by inducing the formation of the intercalary meristem and longitudinal elongation of internode cells. It is presumed that internodes differ in their sensitivity to BRs. OsBRII expression level is greater in the upmost and fourth internodes which allows to respond to the BR signal by inducing elongation. The dm-d6-type dwarfism caused by the severe allele of $d 61$ may be explained by the uppermost internode being exposed to more BRs than the fourth internode. Although BRs are not transported over long distances in the plant, it is possible that large quantities of BRs could move downward from the anthers to the lower organs, including the uppermost internode, and there induce internode elongation (Morinaka et al. 2006; Yamamuro et al. 2000). In addition to BR-insensitive mutants, dm-type dwarfism is also displayed by BR-biosynthetic mutants $d 2$ and $d 11$ (Hong et al. 2003; Tanabe et al. 2005). As mentioned above, the $d l$ mutant (mutated in RGA1) was originally described as a GA signal transduction mutant. Interestingly, $d l$ shows dm-type dwarfism, suggesting that a specific mechanism links BR and GA action in the second internode (Ashikari et al. 1999; Fujisawa et al. 1999; Urano et al. 2013).

\section{Leaf angle}

Leaf angle is an important agronomic trait associated with photosynthesis. It is well known that plants with erect leaves can capture more light for photosynthesis and enable more dense plantings with a higher leaf area index, all of which contribute to increase yields (Sinclair and Sheehy 1999). In rice, the contribution of lower leaves to photosynthesis is still significant even though the photosynthetic capacity of lower leaves is lower than that of upper leaves 
(Horton 2000). Erect leaves allow greater penetration of light to lower leaves and avoid the yield ceiling optimizing canopy photosynthesis.

Two main hormones, BRs and auxin, have been reported to be involved in determining leaf angle in rice (Nakamura et al. 2009). In physiological experiments, the degree of lamina inclination is a good indicator of the concentration of BRs in vivo (Wada et al. 1981). BR-deficient and insensitive mutants show erect leaves, whereas overexpression of BR biosynthetic genes and signaling components increases leaf inclination (Bai et al. 2007; Hong et al. 2005; Yamamuro et al. 2000). For example, the $d 61$ mutant, which is defective in BR perception, displays erect leaves. In this case, longitudinal elongation of surface cells on the adaxial side of the lamina causes the lamina inclination. RAV-LIKE 1 (RAVL1) maintains BR homeostasis via the coordinated activation of OsBRII and biosynthetic genes $D 2, D 11$ and $B R D 1$ in rice, and the ravll mutant has dark-green and erect leaves. The number and size of bulliform cells is also increased in the ravll mutant, similar to in the BR-deficient dwarf 1 (brdl) mutant (Hong et al. 2002; Je et al. 2010). OsBU1 controls bending of the lamina joint downstream of OsBRI1 and OsD1/RGA1 (Tanaka et al. 2009). A new member of the GRAS family, OsGRAS19, was reported to be a positive regulator in the BR-signaling pathway. OsGRAS19 RNAi plants exhibited erect leaves and panicles and OsGRAS19-overexpressing plants displayed narrow leaves, larger leaf angles, and thin culms and panicle stems (Chen et al. 2013).

Other recent insights into the mechanism of leaf angle determination have emphasized the importance of auxin as well as BRs. OsLC1 (LEAF INCLINATION 1) is transcribed in various tissues and encodes OsGH3-1, an indole-3-acetic acid (IAA) amido synthetase, whose homolog functions in maintaining the auxin homeostasis by conjugating excess IAA to amino acids in Arabidopsis. The dominant mutant lc $1-D$ is insensitive to IAA and hypersensitive to exogenous $\mathrm{BR}$, in agreement with the microarray data that suggests the altered transcription levels of genes involved in auxin signaling and BR biosynthesis. These results indicate that auxin homeostasis plays crucial roles in leaf inclination control (Zhao et al. 2012). The OsLC2 (LEAF INCLINATION 2) gene encodes a putative vernalization insensitive 3 -like protein. The $l c 2$ mutants display enlarged leaf angles with increased cell division in the adaxial side of lamina joint. $L C 2$ is response to various hormones such as abscisic acid, gibberellic acid, auxin, and BRs, and mainly expressed in the lamina joint (Zhao et al. 2010). ilil-D was identified as having a large leaf angle in a screen of rice T-DNA insertion mutants. ilil-D displays increased lamina joint bending and hypersensitivity to BR, which are caused by overexpression of the HLH transcription factor OsILI1. Another bHLH transcription factor, OsIBH1, an OsILI1binding protein, inhibits cell elongation to decrease lamina joint bending. While OsLIC represses transcription of OsILI1, OsBZR1 represses OsIBHI as described above (Zhang et al. 2009a; Zhang et al. 2012a). These antagonistic transcription factors are good potential candidate genes for breeders hoping to design optimal rice architecture (Fig. 2) (Zhang et al. 2009a; Zhang et al. 2012a).

\section{Tiller number}

Tillering is an organegenesis process and one of the key agronomic traits. Tiller number per plant determines panicle number, a key component of grain yield. Rice tillering occurs in a two-stage process: the formation of an axillary bud at each leaf axil and its subsequent outgrowth (Li et al. 2003). Normally, a tiller bud arises from the axil of each leaf on the mother stem of a rice plant. Only those on the unelongated basal internodes have the potential to develop into tillers, whereas those formed on the elongated upper internodes become arrested when the mother stems begin to differentiate their own panicles (Wang and Li 2005). Generally, auxin and strigolactone as well as BRs are involved in tillering and branching in rice and Arabidopsis (Zuo and Li 2013). Rice tiller number and height are normally negatively related, i.e. dwarf plants usually have more tillers and vice versa, although there is no genetic evidence for a relationship between height and tillering. Most BR-related dwarf mutants do have more tillers than wild type with the exception of dlt (dwarf and low-tillering) (Tong et al. 2009). dlt is a semi-dwarf mutant with fewer tillers and dark-green, erect leaves. Lamina joint bending and coleoptile elongation assays showed that $d l t$ has reduced sensitivity to BR. OsDLT is a GRAS family protein, and can repress the expression of some BR biosynthesis genes. BR treatment inhibits the transcription of OsDLT. OsBZR1, as a key transcription factor in BR signaling, can bind the promoter of $O S D L T$ to repress its expression (Tong et al. 2009). It is possible that BR, acting through OsBZR1, regulates the expression of $O s D L T$ and thereby controls rice tillering. In BR-deficient or -insensitive mutants, the activity of OsBZR 1 would be inhibited by OsBIN2 phosphorylation, leading to high expression of $O s D L T$, thus inhibiting tillering. The increased expression of $O s D L T$ in $d 2$ and $d 11$ supports this possibility (Tong et al. 2009). However, tissue-specific expression of the BR biosynthesis gene $D W F 4$ in rice can increase the tiller number, suggesting that $\mathrm{BR}$ promotes rice tillering $(\mathrm{Wu}$ et al. 2008). This result is contrast with the possibility that BR inhibits the expression of $O S D L T$ to reduce tiller 
number. It may be explained by a complex interaction between BR and other hormones.

\section{Stress response}

It is known that BRs induce disease resistance in rice. Lossof-function of OsGSK1 improves tolerance of cold, heat, salt and drought stresses compared with the wild type, but the underlying mechanisms remain elusive (Nakashita et al. 2003). Recently, several studies revealed that BR signaling and innate immunity-signaling pathways share multiple components including BAK1, BSK1 and BOTRYTISINDUCED KINASE 1 (BIK1) (Albrecht et al. 2012; Belkhadir et al. 2012; Lin et al. 2013; Shi et al. 2013) (Chinchilla et al. 2007; Heese et al. 2007; Wang 2012). Flagellin 22 (flg22) and chitin are well-characterized pathogen- and microbial-associated molecular patterns (PAMPs and MAMPs) that are important in biotic stress signaling. The binding of flg22 to its receptor FLS2 (flgsensing 2) triggers an association and transphosphorylation with BAK1, thereby activating FLS2, similar to the BRinduction of BRI1 signaling. Then, the activated FLS2 phosphorylates BSK1 and BIK1 to trigger the target responses (Chinchilla et al. 2007; Lu et al. 2010; Sun et al. 2013; Zhang et al. 2010).

The coreceptor BAK1 functions both in BR-induced BRI1 signaling and flg22-induced FLS2 signaling. However, a recent study has suggested the existence of BAK1independent immune signaling, and another study also provided evidence that BRs participate in MTI (MAMPtriggered immunity) through both BAK1-dependent and independent pathways. The association of BRs with MTI responses depends on endogenous BR and BRI1 levels (Albrecht et al. 2012; Belkhadir et al. 2012). In addition, the effects of BRs on stress tolerance depend on the concentration of BRs applied to the plants. Excessive levels of BRs may have detrimental consequences because appropriate levels of BRs are required for optimal BR signaling. Through hormone crosstalk, both BRs and ABA promote stomatal closure, which is likely mediated by nitric oxide (NO). Indeed, NO was shown to mediate both ABAinduced stomatal closure and BR-induced ABA biosynthesis (Choudhary et al. 2012; Cui et al. 2011; Haubrick et al. 2006; Ribeiro et al. 2009; Zhang et al. 2011).

\section{Grain size}

BR-related mutants often showed altered seed size. OsDWARF11 (D11) encodes a novel cytochrome (CYP724B1) and the $d 11$ mutant bears seeds of reduced length and equal width. The highest levels of OsD11 expression were found in the internodes and the florets before flowering, and may correlate with the small-grain phenotype (Tanabe et al. 2005). Other mutants defective in BR biosynthesis, such as $d 2$ and $b r d l$, bear small seeds that are shorter in both length and width (Hong et al. 2002, 2003). The $d l$ mutant, which is deficient in RGAl as described above, bears small seeds similar to those of $d 11$, implying a potential relationship between BR signaling and G-protein-coupled pathways (Oki et al. 2009a, b). Rice plants overexpressing OsILII and OSBUI/ILI4 show enhanced bending of the lamina joint and increased grain size (Tanaka et al. 2009). The dominant short-grain mutant Short grain 1 ( $\mathrm{Sg} 1)$ was identified via phenotypic screening of 13,000 rice activation-tagged lines. The causative gene, $O s S G 1$, encodes a protein with unknown function that is preferentially expressed in roots and developing panicles. Overexpression of $O S S G 1$ in rice produces a phenotype with short grains and dwarfing reminiscent of BR-deficient mutants. Thus, OsSG1 appears to suppress responses to BRs. Despite shorter organs in the SG1:OX plants, cell size is not decreased. Therefore, SG1 decreases organ elongation by decreasing cell proliferation. In contrast to the $S G 1: O X$ plants, RNA interference knockdown plants in which $O S S G 1$ and a related gene, OSSG1-LIKE PROTEIN1, are down-regulated have longer grains and internodes in rachis branches than the wild type. Therefore, SG1 decreases responses to BRs and elongation of organs and the internodes of rachis branches through decreased cellular proliferation (Nakagawa et al. 2012).

\section{Biomass and grain yield}

Since their discovery in 1979, BRs have been considered promising compounds for application in agriculture and their economic value as yield-promoting agents was predicted by the early 1990s (Khripach et al. 2000). Treatment of rice plantlets with 24-epibrassinolide, a synthetic BR, leads to an increase of $22 \%$ in seed fresh weight and of $31.5 \%$ in seed dry weight per plant. BL treatment also increases plant growth rate, root size, and dry weight of root and stem (Zullo and Adam 2002). However, the high cost of synthetic BRs together with the variability of results has discouraged their use in agriculture. By contrast, modulating endogenous BR activity by direct manipulation of genes involved in either BR biosynthesis or signaling could allow for better crop yield and plant performance in a uniform and predictable manner (Divi and Krishna 2009).

BR-deficient and -insensitive mutants displaying dwarfism, erect leaves and reduced fertility are not a viable option for manipulating yield. However, the plants with slightly decreased BR levels or slightly suppressed BR signaling could be useful to increase yields significantly. For instance, the weak mutant allele $d 61-7$ causes a $35 \%$ increase in biomass as compared to wild type at 
high planting density, although there is no difference in grain yield because of the small grain size in d61-7 (Morinaka et al. 2006). To overcome the small-grain phenotype, Morinaka et al. used a co-suppression strategy to reduce the expression of endogenous OsBRII, and two transgenic lines, BKD11 and BKD22, which display erect leaves and normal seed size, were selected. The estimated grain yield of these transformants is $30 \%$ higher than that of wild type at high density. In addition, OsDWARF4 controls BR biosynthesis to influence lamina joint bending. The osdwarf4-1 mutant shows erect leaves and normal reproductive development. Under high-density planting conditions, biomass and grain yield in osdwarf4-1 are increased by nearly 40 and $26 \%$, respectively, over wild type (Sakamoto et al. 2006). These results demonstrate the feasibility of generating erect-leaf plants without defects in reproductive development by reducing the expression of the BR receptor or biosynthesis gene.

Photosynthesis and carbon fixation are also important in determining biomass. Rice plants severely deficient in or insensitive to BRs exhibit reduced leaf area and harvest indices, again making it seem unlikely that a reduction in overall BR levels could result in higher per-plant grain yields. However, manipulation of BR levels in specific parts of crop plants such as those affecting photosynthesis and assimilation could be one way to increase grain yields further. BRs regulate the initial carboxylation activity of ribulose-1, 5-bisphosphate carboxylase/oxygenase (Rubisco) and thereby influence photosynthetic $\mathrm{CO}_{2}$ assimilation (Yu et al. 2004). The expression of DWARF4 (DWF4) is under tight transcriptional/post-transcriptional regulation to maintain BR homeostasis (Kim et al. 2006). In rice, ectopic overexpression of Arabidopsis, rice or maize DWF4 under the control of the S-ADENOSYLMETHIONINE SYNTHASE promoter $(\mathrm{p} A S)$, which is active in the stems, leaves and roots of rice plants, results in between 15 and $44 \%$ increases in grain yield. Microarray and photosynthetic analysis of transgenic plants revealed that enhanced $\mathrm{CO}_{2}$ assimilation, glucose accumulation are enhanced in the flag leaves, which causes increased assimilation of glucose into starch in the seed. These results further suggest that BRs stimulate the flow of assimilate (Wu et al. 2008). All of these findings demonstrate that BRs have the ability to control rice architecture and the flow of assimilate to influence yield. Therefore, genetic modulation of BR activity could be a practical strategy for generating highyield transgenic rice.

\section{Perspectives}

Although recent research has elucidated most of the BRsignaling pathway in rice from the receptor OsBRI1 to the transcription factor OsBZR1, the key regulators of BR- induced responses and the mechanisms behind the pleiotropic actions of BRs remain poorly understood. So far, transcriptional analyses have identified hundreds of potential BR targets, shedding light on the complex activity of BRs in rice (Zhu et al. 2012). Targeted genetic engineering to modulate BR biosynthesis and BR signaling is a promising tool to improve biomass and stress tolerance in rice.

Acknowledgments We thank all of our colleagues who have contributed to this field and apologize to those whose work was not cited because of space limitations.

Conflict of interest The authors declare that they have no conflict of interest.

Open Access This article is distributed under the terms of the Creative Commons Attribution License which permits any use, distribution, and reproduction in any medium, provided the original author(s) and the source are credited.

\section{References}

Albrecht C, Boutrot F, Segonzac C, Schwessinger B, Gimenez-Ibanez S, Chinchilla D, Rathjen JP, de Vries SC, Zipfel C (2012) Brassinosteroids inhibit pathogen-associated molecular patterntriggered immune signaling independent of the receptor kinase BAK1. Proc Natl Acad Sci USA 109:303-308

Ashikari M, Wu J, Yano M, Sasaki T, Yoshimura A (1999) Rice gibberellin-insensitive dwarf mutant gene Dwarf 1 encodes the alpha-subunit of GTP-binding protein. Proc Natl Acad Sci USA 96:10284-10289

Bai MY, Zhang LY, Gampala SS, Zhu SW, Song WY, Chong K, Wang ZY (2007) Functions of OsBZR1 and 14-3-3 proteins in brassinosteroid signaling in rice. Proc Natl Acad Sci USA 104:13839-13844

Bai MY, Shang JX, Oh E, Fan M, Bai Y, Zentella R, Sun TP, Wang ZY (2012) Brassinosteroid, gibberellin and phytochrome impinge on a common transcription module in Arabidopsis. Nat Cell Biol 14:810-817

Belkhadir Y, Jaillais Y, Epple P, Balsemao-Pires E, Dangl JL, Chory J (2012) Brassinosteroids modulate the efficiency of plant immune responses to microbe-associated molecular patterns. Proc Natl Acad Sci USA 109:297-302

Bishop GJ, Nomura T, Yokota T, Harrison K, Noguchi T, Fujioka S, Takatsuto S, Jones JD, Kamiya Y (1999) The tomato DWARF enzyme catalyses C-6 oxidation in brassinosteroid biosynthesis. Proc Natl Acad Sci USA 96:1761-1766

Chen L, Xiong G, Cui X, Yan M, Xu T, Qian Q, Xue Y, Li J, Wang Y (2013) OsGRAS19 may be a novel component involved in the brassinosteroid signaling pathway in rice. Mol Plant 6(3):988-991

Chinchilla D, Zipfel C, Robatzek S, Kemmerling B, Nurnberger T, Jones JD, Felix G, Boller T (2007) A flagellin-induced complex of the receptor FLS2 and BAK1 initiates plant defence. Nature 448:497-500

Choe S, Dilkes BP, Fujioka S, Takatsuto S, Sakurai A, Feldmann KA (1998) The DWF4 gene of Arabidopsis encodes a cytochrome P450 that mediates multiple 22alpha-hydroxylation steps in brassinosteroid biosynthesis. Plant Cell 10:231-243

Choe S, Fujioka S, Noguchi T, Takatsuto S, Yoshida S, Feldmann KA (2001) Overexpression of DWARF4 in the brassinosteroid 
biosynthetic pathway results in increased vegetative growth and seed yield in Arabidopsis. Plant J 26:573-582

Choi YH, Fujioka S, Harada A, Yokota T, Takatsuto S, Sakurai A (1996) A brassinolide biosynthetic pathway via 6-deoxocastasterone. Phytochemistry 43:593-596

Choudhary SP, Yu JQ, Yamaguchi-Shinozaki K, Shinozaki K, Tran LS (2012) Benefits of brassinosteroid crosstalk. Trends Plant Sci 17:594-605

Clouse SD (2011) Brassinosteroid signal transduction: from receptor kinase activation to transcriptional networks regulating plant development. Plant Cell 23:1219-1230

Clouse SD, Sasse JM (1998) BRASSINOSTEROIDS: essential regulators of plant growth and development. Annu Rev Plant Physiol Plant Mol Biol 49:427-451

Cui JX, Zhou YH, Ding JG, Xia XJ, Shi K, Chen SC, Asami T, Chen Z, Yu JQ (2011) Role of nitric oxide in hydrogen peroxidedependent induction of abiotic stress tolerance by brassinosteroids in cucumber. Plant Cell Environ 34:347-358

De Vleesschauwer D, Van Buyten E, Satoh K, Balidion J, Mauleon R, Choi IR, Vera-Cruz C, Kikuchi S, Hofte M (2012) Brassinosteroids antagonize gibberellin- and salicylate-mediated root immunity in rice. Plant Physiol 158:1833-1846

Deng Z, Zhang X, Tang W, Oses-Prieto JA, Suzuki N, Gendron JM, Chen H, Guan S, Chalkley RJ, Peterman TK, Burlingame AL, Wang ZY (2007) A proteomics study of brassinosteroid response in Arabidopsis. Mol Cell Proteomics 6:2058-2071

Di Rubbo S, Irani NG, Russinova E (2011) PP2A phosphatases: the "on-off" regulatory switches of brassinosteroid signaling. Sci Signal 4:pe25

Divi UK, Krishna P (2009) Brassinosteroid: a biotechnological target for enhancing crop yield and stress tolerance. N Biotechnol 26:131-136

Fujioka S, Sakurai A (1997) Brassinosteroids. Nat Prod Rep 14:1-10

Fujioka S, Noguchi T, Watanabe T, Takatsuto S, Yoshida S (2000) Biosynthesis of brassinosteroids in cultured cells of Catharanthus roseus. Phytochemistry 53:549-553

Fujioka S, Yokota T (2003) Biosynthesis and metabolism of brassinosteroids. Annu Rev Plant Biol 54:137-164

Fujisawa Y, Kato T, Ohki S, Ishikawa A, Kitano H, Sasaki T, Asahi T, Iwasaki Y (1999) Suppression of the heterotrimeric G protein causes abnormal morphology, including dwarfism, in rice. Proc Natl Acad Sci USA 96:7575-7580

Gao Y, Wang S, Asami T, Chen JG (2008) Loss-of-function mutations in the Arabidopsis heterotrimeric G-protein alpha subunit enhance the developmental defects of brassinosteroid signaling and biosynthesis mutants. Plant Cell Physiol 49:1013-1024

Grove MD, Spencer GF, Rowedder WK, Mandava N, Worley J F, Warthen J D Jr, Steffens GL, Flippen-Anderson JL, Cook JK Jr (1979) Brassinolide, a plant growth promoting steroid isolated from Brassica napus pollen. Nature 281:216-217

Guo Z, Fujioka S, Blancaflor EB, Miao S, Gou X, Li J (2010) TCP1 modulates brassinosteroid biosynthesis by regulating the expression of the key biosynthetic gene DWARF4 in Arabidopsis thaliana. Plant Cell 22:1161-1173

Hao J, Yin Y, Fei SZ (2013) Brassinosteroid signaling network: implications on yield and stress tolerance. Plant Cell Rep 32:1017-1030

Haubrick LL, Torsethaugen G, Assmann SM (2006) Effect of brassinolide, alone and in concert with abscisic acid, on control of stomatal aperture and potassium currents of Vicia faba guard cell protoplasts. Physiol Plant 128:134-143

He JX, Gendron JM, Yang Y, Li J, Wang ZY (2002) The GSK3-like kinase BIN2 phosphorylates and destabilizes BZR1, a positive regulator of the brassinosteroid signaling pathway in Arabidopsis. Proc Natl Acad Sci USA 99:10185-10190
He JX, Gendron JM, Sun Y, Gampala SS, Gendron N, Sun CQ, Wang ZY (2005) BZR1 is a transcriptional repressor with dual roles in brassinosteroid homeostasis and growth responses. Science 307:1634-1638

Heese A, Hann DR, Gimenez-Ibanez S, Jones AM, He K, Li J, Schroeder JI, Peck SC, Rathjen JP (2007) The receptor-like kinase SERK3/BAK1 is a central regulator of innate immunity in plants. Proc Natl Acad Sci USA 104:12217-12222

Hong Z, Ueguchi-Tanaka M, Shimizu-Sato S, Inukai Y, Fujioka S, Shimada Y, Takatsuto S, Agetsuma M, Yoshida S, Watanabe Y, Uozu S, Kitano H, Ashikari M, Matsuoka M (2002) Loss-of-function of a rice brassinosteroid biosynthetic enzyme, C-6 oxidase, prevents the organized arrangement and polar elongation of cells in the leaves and stem. Plant $\mathbf{J}$ 32:495-508

Hong Z, Ueguchi-Tanaka M, Umemura K, Uozu S, Fujioka S, Takatsuto S, Yoshida S, Ashikari M, Kitano H, Matsuoka M (2003) A rice brassinosteroid-deficient mutant, ebisu dwarf (d2), is caused by a loss of function of a new member of cytochrome P450. Plant Cell 15:2900-2910

Hong Z, Ueguchi_tanaka M, Matsuoka M (2004) Brassinosteroids and rice architecture. J Pestic Sci 29:184-187

Hong Z, Ueguchi-Tanaka M, Fujioka S, Takatsuto S, Yoshida S, Hasegawa Y, Ashikari M, Kitano H, Matsuoka M (2005) The Rice brassinosteroid-deficient dwarf 2 mutant, defective in the rice homolog of Arabidopsis DIMINUTO/DWARF1, is rescued by the endogenously accumulated alternative bioactive brassinosteroid, dolichosterone. Plant Cell 17:2243-2254

Horton P (2000) Prospects for crop improvement through the genetic manipulation of photosynthesis: morphological and biochemical aspects of light capture. J Exp Bot 51 Spec No:475-485

Hothorn M, Belkhadir Y, Dreux M, Dabi T, Noel JP, Wilson IA, Chory J (2011) Structural basis of steroid hormone perception by the receptor kinase BRI1. Nature 474:467-471

Hu MY (2011) Brassinosteroids and auxin down-regulate DELLA genes in fiber initiation and elongation of cotton. Agr Sci China 10:1168-1176

Hu X, Qian Q, Xu T, Zhang Y, Dong G, Gao T, Xie Q, Xue Y (2013) The U-box E3 ubiquitin ligase TUD1 functions with a heterotrimeric $G$ alpha subunit to regulate brassinosteroid-mediated growth in rice. PLoS Genet 9:e1003391

Ikekawa N, Zhao YJ (1991) Application of 24-epibrassinolide in agriculture. ACS Symp Ser 474:280-291

Jaillais Y, Hothorn M, Belkhadir Y, Dabi T, Nimchuk ZL, Meyerowitz EM, Chory J (2011) Tyrosine phosphorylation controls brassinosteroid receptor activation by triggering membrane release of its kinase inhibitor. Genes Dev 25:232-237

Je BI, Piao HL, Park SJ, Park SH, Kim CM, Xuan YH, Huang J, Do Choi Y, An G, Wong HL, Fujioka S, Kim MC, Shimamoto K, Han CD (2010) RAV-Like1 maintains brassinosteroid homeostasis via the coordinated activation of BRI1 and biosynthetic genes in rice. Plant Cell 22:1777-1791

Kang JG, Yun J, Kim DH, Chung KS, Fujioka S, Kim JI, Dae HW, Yoshida S, Takatsuto S, Song PS, Park CM (2001) Light and brassinosteroid signals are integrated via a dark-induced small $\mathrm{G}$ protein in etiolated seedling growth. Cell 105:625-636

Khripach V, Zhabinskii VN, Groot AD (2000) Twenty years of brassinosteroids: steroidal plant hormones warrant better crops for the XXI century. Ann Bot 86:441-447

Kim HB, Kwon M, Ryu H, Fujioka S, Takatsuto S, Yoshida S, An CS, Lee I, Hwang I, Choe S (2006) The regulation of DWARF4 expression is likely a critical mechanism in maintaining the homeostasis of bioactive brassinosteroids in Arabidopsis. Plant Physiol 140:548-557

Kim TW, Guan S, Sun Y, Deng Z, Tang W, Shang JX, Burlingame AL, Wang ZY (2009) Brassinosteroid signal transduction from 
cell-surface receptor kinases to nuclear transcription factors. Nat Cell Biol 11:1254-1260

Kim TW, Guan S, Burlingame AL, Wang ZY (2011) The CDG1 kinase mediates brassinosteroid signal transduction from BRI1 receptor kinase to BSU1 phosphatase and GSK3-like kinase BIN2. Mol Cell 43:561-571

Kinoshita T, Cano-Delgado A, Seto H, Hiranuma S, Fujioka S, Yoshida S, Chory J (2005) Binding of brassinosteroids to the extracellular domain of plant receptor kinase BRI1. Nature 433:167-171

Koh S, Lee SC, Kim MK, Koh JH, Lee S, An G, Choe S, Kim SR (2007) T-DNA tagged knockout mutation of rice OsGSK1, an orthologue of Arabidopsis BIN2, with enhanced tolerance to various abiotic stresses. Plant Mol Biol 65:453-466

Koka CV, Cerny RE, Gardner RG, Noguchi T, Fujioka S, Takatsuto S, Yoshida S, Clouse SD (2000) A putative role for the tomato genes DUMPY and CURL-3 in brassinosteroid biosynthesis and response. Plant Physiol 122:85-98

Kwon MCS (2005) Brassinosteroid biosynthesis and dwarf mutants. J Plant Biol 48:1-15

Li J (2010) Regulation of the nuclear activities of brassinosteroid signaling. Curr Opin Plant Biol 13:540-547

Li J, Chory J (1997) A putative leucine-rich repeat receptor kinase involved in brassinosteroid signal transduction. Cell 90:929-938

Li J, Nam KH (2002) Regulation of brassinosteroid signaling by a GSK3/SHAGGY-like kinase. Science 295:1299-1301

Li J, Wen J, Lease KA, Doke JT, Tax FE, Walker JC (2002) BAK1, an Arabidopsis LRR receptor-like protein kinase, interacts with BRI1 and modulates brassinosteroid signaling. Cell 110:213-222

Li X, Qian Q, Fu Z, Wang Y, Xiong G, Zeng D, Wang X, Liu X, Teng S, Hiroshi F, Yuan M, Luo D, Han B, Li J (2003) Control of tillering in rice. Nature 422:618-621

Li D, Wang L, Wang M, Xu YY, Luo W, Liu YJ, Xu ZH, Li J, Chong $\mathrm{K}$ (2009) Engineering OsBAK1 gene as a molecular tool to improve rice architecture for high yield. Plant Biotechnol J 7:791-806

Li L, Ye H, Guo H, Yin Y (2010) Arabidopsis IWS1 interacts with transcription factor BES1 and is involved in plant steroid hormone brassinosteroid regulated gene expression. Proc Natl Acad Sci USA 107:3918-3923

Lin W, Lu D, Gao X, Jiang S, Ma X, Wang Z, Mengiste T, He P, Shan L (2013) Inverse modulation of plant immune and brassinosteroid signaling pathways by the receptor-like cytoplasmic kinase BIK1. Proc Natl Acad Sci USA 110:12114-12119

Lu D, Wu S, Gao X, Zhang Y, Shan L, He P (2010) A receptor-like cytoplasmic kinase, BIK1, associates with a flagellin receptor complex to initiate plant innate immunity. Proc Natl Acad Sci USA 107:496-501

Mora-Garcia S, Vert G, Yin Y, Cano-Delgado A, Cheong H, Chory J (2004) Nuclear protein phosphatases with Kelch-repeat domains modulate the response to brassinosteroids in Arabidopsis. Genes Dev 18:448-460

Mori M, Nomura T, Ooka H, Ishizaka M, Yokota T, Sugimoto K, Okabe K, Kajiwara H, Satoh K, Yamamoto K, Hirochika H, Kikuchi S (2002) Isolation and characterization of a rice dwarf mutant with a defect in brassinosteroid biosynthesis. Plant Physiol 130:1152-1161

Morinaka Y, Sakamoto T, Inukai Y, Agetsuma M, Kitano H, Ashikari M, Matsuoka M (2006) Morphological alteration caused by brassinosteroid insensitivity increases the biomass and grain production of rice. Plant Physiol 141:924-931

Mouchel CF, Osmont KS, Hardtke CS (2006) BRX mediates feedback between brassinosteroid levels and auxin signalling in root growth. Nature 443:458-461

Nakagawa H, Tanaka A, Tanabata T, Ohtake M, Fujioka S, Nakamura H, Ichikawa H, Mori M (2012) Short grain1 decreases organ elongation and brassinosteroid response in rice. Plant Physiol 158:1208-1219

Nakamura A, Fujioka S, Sunohara H, Kamiya N, Hong Z, Inukai Y, Miura K, Takatsuto S, Yoshida S, Ueguchi-Tanaka M, Hasegawa Y, Kitano H, Matsuoka M (2006) The role of OsBRI1 and its homologous genes, OsBRL1 and OsBRL3, in rice. Plant Physiol 140:580-590

Nakamura A, Fujioka S, Takatsuto S, Tsujimoto M, Kitano H, Yoshida S, Asami T, Nakano T (2009) Involvement of C-22hydroxylated brassinosteroids in auxin-induced lamina joint bending in rice. Plant Cell Physiol 50:1627-1635

Nakashita H, Yasuda M, Nitta T, Asami T, Fujioka S, Arai Y, Sekimata K, Takatsuto S, Yamaguchi I, Yoshida S (2003) Brassinosteroid functions in a broad range of disease resistance in tobacco and rice. Plant J 33:887-898

Nam KH, Li J (2002) BRI1/BAK1, a receptor kinase pair mediating brassinosteroid signaling. Cell 110:203-212

Noguchi T, Fujioka S, Choe S, Takatsuto S, Tax FE, Yoshida S, Feldmann KA (2000) Biosynthetic pathways of brassinolide in Arabidopsis. Plant Physiol 124:201-209

Ohnishi T, Szatmari AM, Watanabe B, Fujita S, Bancos S, Koncz C, Lafos M, Shibata K, Yokota T, Sakata K, Szekeres M, Mizutani M (2006) C-23 hydroxylation by Arabidopsis CYP90C1 and CYP90D1 reveals a novel shortcut in brassinosteroid biosynthesis. Plant Cell 18:3275-3288

Ohnishi T, Godza B, Watanabe B, Fujioka S, Hategan L, Ide K, Shibata K, Yokota T, Szekeres M, Mizutani M (2012) CYP90A1/CPD, a brassinosteroid biosynthetic cytochrome P450 of Arabidopsis, catalyzes C-3 oxidation. J Biol Chem 287:31551-31560

Oki K, Inaba N, Kitano H, Takahashi S, Fujisawa Y, Kato H, Iwasaki Y (2009a) Study of novel d1 alleles, defective mutants of the alpha subunit of heterotrimeric G-protein in rice. Genes Genet Syst 84:35-42

Oki K, Kitagawa K, Fujisawa Y, Kato H, Iwasaki Y (2009b) Function of alpha subunit of heterotrimeric $\mathrm{G}$ protein in brassinosteroid response of rice plants. Plant Signal Behav 4:126-128

Poppenberger B, Rozhon W, Khan M, Husar S, Adam G, Luschnig C, Fujioka S, Sieberer T (2011) CESTA, a positive regulator of brassinosteroid biosynthesis. EMBO J 30:1149-1161

Ribeiro DM, Desikan R, Bright JO, Confraria ANA, Harrison J, Hancock JT, Barros RS, Neill SJ, Wilson ID (2009) Differential requirement for $\mathrm{NO}$ during $\mathrm{ABA}$-induced stomatal closure in turgid and wilted leaves. Plant Cell Environ 32:46-57

Sakamoto T, Matsuoka M (2004) Generating high-yielding varieties by genetic manipulation of plant architecture. Curr Opin Biotechnol 15:144-147

Sakamoto T, Matsuoka M (2006) Characterization of CONSTITUTIVE PHOTOMORPHOGENESIS AND DWARFISM homologs in rice (Oryza sativa L.). J Plant Growth Regul 25:245-251

Sakamoto T, Morinaka Y, Ohnishi T, Sunohara H, Fujioka S, Ueguchi-Tanaka M, Mizutani M, Sakata K, Takatsuto S, Yoshida S, Tanaka H, Kitano H, Matsuoka M (2006) Erect leaves caused by brassinosteroid deficiency increase biomass production and grain yield in rice. Nat Biotechnol 24:105-109

Sakamoto T, Ohnishi T, Fujioka S, Watanabe B, Mizutani M (2012) Rice CYP90D2 and CYP90D3 catalyze C-23 hydroxylation of brassinosteroids in vitro. Plant Physiol Biochem 58:220-226

Santiago J, Henzler C, Hothorn M (2013) Molecular mechanism for plant steroid receptor activation by somatic embryogenesis coreceptor kinases. Science 341:889-892

Sasse JM (2003) Physiological actions of brassinosteroids: an update. J Plant Growth Regul 22:276-288

She J, Han Z, Kim TW, Wang J, Cheng W, Chang J, Shi S, Yang M, Wang ZY, Chai J (2011) Structural insight into brassinosteroid perception by BRI1. Nature 474:472-476 
Shi H, Shen Q, Qi Y, Yan H, Nie H, Chen Y, Zhao T, Katagiri F, Tang D (2013) BR-Signaling KinaSE1 physically associates with Flagellin Sensing2 and regulates plant innate immunity in Arabidopsis. Plant Cell 25:1143-1157

Shimada Y, Fujioka S, Miyauchi N, Kushiro M, Takatsuto S, Nomura T, Yokota T, Kamiya Y, Bishop GJ, Yoshida S (2001) Brassinosteroid-6-oxidases from Arabidopsis and tomato catalyze multiple C-6 oxidations in brassinosteroid biosynthesis. Plant Physiol 126:770-779

Sinclair T, Sheehy J (1999) Erect leaves and photosynthesis in rice. Science 283:2

Sun Y, Fan XY, Cao DM, Tang W, He K, Zhu JY, He JX, Bai MY, Zhu S, Oh E, Patil S, Kim TW, Ji H, Wong WH, Rhee SY, Wang ZY (2010) Integration of brassinosteroid signal transduction with the transcription network for plant growth regulation in Arabidopsis. Dev Cell 19:765-777

Sun Y, Li L, Macho AP, Han Z, Hu Z, Zipfel C, Zhou JM, Chai J (2013) Structural basis for flg22-induced activation of the Arabidopsis FLS2-BAK1 immune complex. Science 342:624-628

Symons GM, Davies C, Shavrukov Y, Dry IB, Reid JB, Thomas MR (2006) Grapes on steroids. Brassinosteroids are involved in grape berry ripening. Plant Physiol 140:150-158

Symons GM, Ross JJ, Jager CE, Reid JB (2008) Brassinosteroid transport. J Exp Bot 59:17-24

Tanabe S, Ashikari M, Fujioka S, Takatsuto S, Yoshida S, Yano MYA, Kitano H, Matsuoka M, Fujisawa Y, Kato HIY (2005) A novel cytochrome $\mathrm{P} 450$ is implicated in brassinosteroid biosynthesis via the characterization of a rice dwarf mutant, dwarf11, with reduced seed length. Plant Cell 17:776-790

Tanaka A, Nakagawa H, Tomita C, Shimatani Z, Ohtake M, Nomura T, Jiang CJ, Dubouzet JG, Kikuchi S, Sekimoto H, Yokota T, Asami T, Kamakura T, Mori M (2009) BRASSINOSTEROID UPREGULATED1, encoding a helix-loop-helix protein, is a novel gene involved in brassinosteroid signaling and controls bending of the lamina joint in rice. Plant Physiol 151:669-680

Tang W, Kim TW, Oses-Prieto JA, Sun Y, Deng Z, Zhu S, Wang R, Burlingame AL, Wang ZY (2008) BSKs mediate signal transduction from the receptor kinase BRI1 in Arabidopsis. Science 321:557-560

Tang W, Yuan M, Wang R, Yang Y, Wang C, Oses-Prieto JA, Kim TW, Zhou HW, Deng Z, Gampala SS, Gendron JM, Jonassen EM, Lillo C, DeLong A, Burlingame AL, Sun Y, Wang ZY (2011) PP2A activates brassinosteroid-responsive gene expression and plant growth by dephosphorylating BZR1. Nat Cell Biol 13(2):124-131

Tong H, Chu C (2012) Brassinosteroid signaling and application in rice. J Genet Genomics 39:3-9

Tong H, Jin Y, Liu W, Li F, Fang J, Yin Y, Qian Q, Zhu L, Chu C (2009) DWARF and LOW-TILLERING, a new member of the GRAS family, plays positive roles in brassinosteroid signaling in rice. Plant J 58:803-816

Tong H, Liu L, Jin Y, Du L, Yin Y, Qian Q, Zhu L, Chu C (2012) DWARF and LOW-TILLERING acts as a direct downstream target of a GSK3/SHAGGY-like kinase to mediate brassinosteroid responses in rice. Plant Cell 24:2562-2577

Ueguchi-Tanaka M, Fujisawa Y, Kobayashi M, Ashikari M, Iwasaki Y, Kitano H, Matsuoka M (2000) Rice dwarf mutant d1, which is defective in the alpha subunit of the heterotrimeric $G$ protein, affects gibberellin signal transduction. Proc Natl Acad Sci USA 97(21):11638-11643

Urano D, Chen JG, Botella JR, Jones AM (2013) Heterotrimeric G protein signalling in the plant kingdom. Open Biol 3:120186

Vriet C, Russinova E, Reuzeau C (2013) From squalene to brassinolide: the steroid metabolic and signaling pathways across the plant kingdom. Mol Plant 6:1738-1757
Wada K, Marumo S, Ikekawa N, Morisaki M, Mori K (1981) Brassinolide and homobrassinolide promotion of lamina inclination of rice seedlings. Plant Cell Physiol 22:323-325

Wang ZY (2012) Brassinosteroids modulate plant immunity at multiple levels. Proc Natl Acad Sci USA 109:7-8

Wang X, Chory J (2006) Brassinosteroids regulate dissociation of BKI1, a negative regulator of BRI1 signaling, from the plasma membrane. Science 313:1118-1122

Wang Y, Li J (2005) The plant architecture of rice (Oryza sativa). Plant Mol Biol 59:75-84

Wang ZY, Seto H, Fujioka S, Yoshida S, Chory J (2001) BRI1 is a critical component of a plasma-membrane receptor for plant steroids. Nature 410:380-383

Wang ZY, Nakano T, Gendron J, He J, Chen M, Vafeados D, Yang Y, Fujioka S, Yoshida S, Asami T, Chory J (2002) Nuclear-localized BZR1 mediates brassinosteroid-induced growth and feedback suppression of brassinosteroid biosynthesis. Dev Cell 2:505-513

Wang L, Xu YY, Ma QB, Li D, Xu ZH, Chong K (2006) Heterotrimeric $G$ protein alpha subunit is involved in rice brassinosteroid response. Cell Res 16:916-922

Wang L, Xu YY, Li J, Powell RA, Xu ZH, Chong K (2007) Transgenic rice plants ectopically expressing AtBAK1 are semidwarfed and hypersensitive to 24-epibrassinolide. J Plant Physiol 164:655-664

Wang L, Xu Y, Zhang C, Ma Q, Joo SH, Kim SK, Xu Z, Chong K (2008a) OsLIC, a novel CCCH-type zinc finger protein with transcription activation, mediates rice architecture via brassinosteroids signaling. PLoS One 3:e3521

Wang X, Kota U, He K, Blackburn K, Li J, Goshe MB, Huber SC, Clouse SD (2008b) Sequential transphosphorylation of the BRI1/ BAK1 receptor kinase complex impacts early events in brassinosteroid signaling. Dev Cell 15:220-235

Wang L, Wang Z, Xu Y, Joo SH, Kim SK, Xue Z, Xu Z, Chong K (2009) OsGSR1 is involved in crosstalk between gibberellins and brassinosteroids in rice. Plant J 57:498-510

Wang H, Yang C, Zhang C, Wang N, Lu D, Wang J, Zhang S, Wang ZX, Ma H, Wang X (2011) Dual role of BKI1 and 14-3-3s in brassinosteroid signaling to link receptor with transcription factors. Dev Cell 21:825-834

Wang ZY, Bai MY, Oh E, Zhu JY (2012) Brassinosteroid signaling network and regulation of photomorphogenesis. Annu Rev Genet 46:701-724

Wang Y, Sun S, Zhu W, Jia K, Yang H, Wang X (2013) Strigolactone/MAX2-induced degradation of brassinosteroid transcriptional effector BES1 regulates shoot branching. Dev Cell 27:681-688

Wu CY, Trieu A, Radhakrishnan P, Kwok SF, Harris S, Zhang K, Wang J, Wan J, Zhai H, Takatsuto S, Matsumoto S, Fujioka S, Feldmann KA, Pennell RI (2008) Brassinosteroids regulate grain filling in rice. Plant Cell 20:2130-2145

Wu G, Wang X, Li X, Kamiya Y, Otegui MS, Chory J (2011) Methylation of a phosphatase specifies dephosphorylation and degradation of activated brassinosteroid receptors. Sci Signal 4:ra29

Yamamuro C, Ihara Y, Wu X, Noguchi T, Fujioka S, Takatsuto S, Ashikari M, Kitano H, Matsuoka M (2000) Loss of function of a rice brassinosteroid insensitive 1 homolog prevents internode elongation and bending of the lamina joint. Plant Cell 12:1591-1606

Yin Y, Wang ZY, Mora-Garcia S, Li J, Yoshida S, Asami T, Chory J (2002) BES1 accumulates in the nucleus in response to brassinosteroids to regulate gene expression and promote stem elongation. Cell 109:181-191

Yin Y, Vafeados D, Tao Y, Yoshida S, Asami T, Chory J (2005) A new class of transcription factors mediates brassinosteroidregulated gene expression in Arabidopsis. Cell 120:249-259 
Yu JQ, Huang LF, Hu WH, Zhou YH, Mao WH, Ye SF, Nogues S (2004) A role for brassinosteroids in the regulation of photosynthesis in Cucumis sativus. J Exp Bot 55:1135-1143

Yu X, Li L, Zola J, Aluru M, Ye H, Foudree A, Guo H, Anderson S, Aluru S, Liu P, Rodermel S, Yin Y (2011) A brassinosteroid transcriptional network revealed by genome-wide identification of BESI targetgenes in Arabidopsis thaliana. Plant J 65(4): 634-646

Zhang LY, Bai MY, Wu J, Zhu JY, Wang H, Zhang Z, Wang W, Sun Y, Zhao J, Sun X, Yang H, Xu Y, Kim SH, Fujioka S, Lin WH, Chong K, Lu T, Wang ZY (2009a) Antagonistic HLH/bHLH transcription factors mediate brassinosteroid regulation of cell elongation and plant development in rice and Arabidopsis. Plant Cell 21:3767-3780

Zhang S, Cai Z, Wang X (2009b) The primary signaling outputs of brassinosteroids are regulated by abscisic acid signaling. Proc Natl Acad Sci USA 106:4543-4548

Zhang J, Li W, Xiang T, Liu Z, Laluk K, Ding X, Zou Y, Gao M, Zhang X, Chen S, Mengiste T, Zhang Y, Zhou JM (2010) Receptor-like cytoplasmic kinases integrate signaling from multiple plant immune receptors and are targeted by a Pseudomonas syringae effector. Cell Host Microbe 7:290-301

Zhang A, Zhang J, Ye N, Zhang H, Tan M, Jiang M (2011) Nitric oxide mediates brassinosteroid-induced ABA biosynthesis involved in oxidative stress tolerance in maize leaves. Plant Cell Physiol 52:181-192

Zhang C, Xu Y, Guo S, Zhu J, Huan Q, Liu H, Wang L, Luo G, Wang X, Chong K (2012a) Dynamics of brassinosteroid response modulated by negative regulator LIC in rice. PLoS Genet 8:e1002686

Zhang R, Xia X, Lindsey K, da Rocha PS (2012b) Functional complementation of dwf4 mutants of Arabidopsis by overexpression of CYP724A1. J Plant Physiol 169:421-428

Zhang Y, Li B, Xu Y, Li H, Li S, Zhang D, Mao Z, Guo S, Yang C, Weng Y, Chong K (2013) The cyclophilin CYP20-2 modulates the conformation of BRASSINAZOLE-RESISTANT1, which binds the promoter of FLOWERING LOCUS D to regulate flowering in Arabidopsis. Plant Cell 25:2504-2521

Zhao SQ, Hu J, Guo LB, Qian Q, Xue HW (2010) Rice leaf inclination2, a VIN3-like protein, regulates leaf angle through modulating cell division of the collar. Cell Res 20:935-947

Zhao SQ, Xiang JJ, Xue HW (2012) Studies on the rice leaf INCLINATION1 (LC1), an IAA-amido synthetase, reveal the effects of auxin in leaf inclination control. Mol Plant 6(1):174-187

Zhu JY, Sun Y, Wang ZY (2012) Genome-wide identification of transcription factor-binding sites in plants using chromatin immunoprecipitation followed by microarray (ChIP-chip) or sequencing (ChIP-seq). Methods Mol Biol 876:173-188

Zhu JY, Sae-Seaw J, Wang ZY (2013) Brassinosteroid signalling. Development 140:1615-1620

Zullo MAT, Adam G (2002) Brassinosteroid phytohormonesstructure, bioactivity and applications. Braz J Plant Physiol $14: 143-181$

Zuo JR, Li JY (2013) Molecular dissection of complex agronomic traits of rice: a team effort by Chinese scientists in recent years. Natl Sci Rev. doi:10.1093/nsr/nwt004 